\title{
Inhalt
}

Ludwig M. Eichinger: Sprachliche Vielfalt und gesellschaftliche

Diversität: Das Deutsch der Migranten. VII

Arnulf Deppermann: Einleitung: Das Deutsch der Migranten 1

\section{Migrationsbedingte Sprechweisen}

Peter Auer: Ethnische Marker im Deutschen zwischen

Varietät und Stil

Heike Wiese: Das Potenzial multiethnischer Sprechergemeinschaften.......41

Ben Rampton: From 'Youth Language' to contemporary urban vernaculars

Nina Berend: Varietätenwandel im Kontakt. Die Entwicklung des Sprachgebrauchs deutschsprachiger Minderheiten im bundesdeutschen Kontext

Ibrahim Cindark: Deutsch-türkisches Code-Switching und Code-Mixing in einer Gruppe von akademischen Migranten der zweiten Generation.

\section{Sprachbiographien von Migranten}

Anne Betten: Sprachbiographien deutscher Emigranten. Die „Jeckes“ in Israel zwischen Verlust und Rekonstruktion ihrer kulturellen Identität

Patrick Stevenson: SprachGeschichten mit Migrationshintergrund: demografische und biografische Perspektiven auf Sprachkenntnisse und Spracherleben.

Katharina Brizić: Grenzenlose Biografien und ihr begrenzter (Bildungs-)Erfolg. Das Thema der sozialen Ungleichheit aus der Perspektive eines laufenden soziolinguistischen Forschungsprojekts 
Kommunikation zwischen Zuwanderern und Einheimischen

Ulrich Reitemeier: Zur kommunikativen Realisierung von Differenzorientierung in Situationen zwischen Aussiedlern und Einheimischen

Ludger Hoffmann/Uta Quasthoff: Schreiben zwischen Sprachen und Kulturen. Kommunikation mit und über Behörden

\section{Erwerb des Deutschen als Zweitsprache}

Petra Schulz: Wer versteht wann was? Sprachverstehen im frühen Zweitspracherwerb des Deutschen am Beispiel der w-Fragen

Ulrich Mehlem: Literate und narrative Textgestaltung in der Zweitsprache zwischen Mündlichkeit und Schriftlichkeit Grundschüler türkischer Herkunftssprache erzählen einen Stummfilm auf Deutsch.

Ursula Bredel: Silben und Füße im Deutschen und Türkischen Orthographieerwerb des Deutschen durch türkischsprachige Lerner/innen

Das Deutsch der Migranten - eine Zwischenbilanz (Podiumsdiskussion auf der 48. Jahrestagung des Instituts für Deutsche Sprache) 